\title{
UNDERSTANDING ACCIDENT CAUSATION IN LED OUTDOOR ACTIVITIES: DEVELOPMENT OF AN ACCIDENT ANALYSIS FRAMEWORK
}

doi:10.1136/injuryprev-2012-040590w.53

${ }^{1} \mathrm{PM}$ Salmon, ${ }^{1} \mathrm{~N}$ Goode, ${ }^{1} \mathrm{MG}$ Lenné, ${ }^{2} \mathrm{C}$ Finch, ${ }^{3} \mathrm{E}$ Cassell. ${ }^{1}$ Monash University Accident Research Centre (MUARC), Monash Injury Research Institute (MIRI), Monash University, Melbourne, Australia; ${ }^{2}$ Australian Centre for Research into Injury in Sport and its Prevention (ACRISP), MIRI, Monash University, Melbourne, Australia; ${ }^{3}$ Victorian Injury Surveillance Unit (VISU), MIRI, Monash University, Melbourne, Australia

Background In Australia, injury-causing accidents during led outdoor activities are currently problematic; however, the industry's understanding of accidents is limited and the surveillance systems required to enhance it do not exist. This paper describes the development of a new accident analysis framework for led outdoor activities.

Aims The aim of this research was to develop a new accident analysis framework for led outdoor activities.

Methods Development of the framework was informed by three activities:

1. An analysis of existing led outdoor activity incident data;

2. A review of the accident causation literature; and

3. A review of existing accident analysis methods.

The framework was then tested through analysis of a series of led outdoor activity incidents.

Results The newly developed accident analysis framework comprises taxonomies of causal factors across the following led outdoor activity 'system' levels: Government policy and budgeting, Regulatory bodies and associations, Local area government planning and budgeting and company management, technical and operational management, physical processes and actor activities, and equipment and environment (Rasmussen, 1997). The test applications demonstrate that the framework can be used to identify causal factors across all levels of the led outdoor activity system.

Contribution to the Field The new accident analysis framework provides a theoretically driven, structured methodology for analysing led outdoor activity accidents. Application of the framework will increase the sector's understanding of accidents, which in turn will

support development of more informed and effective countermeasures. The long term contribution will therefore be a reduction in accident and injury rates. 